
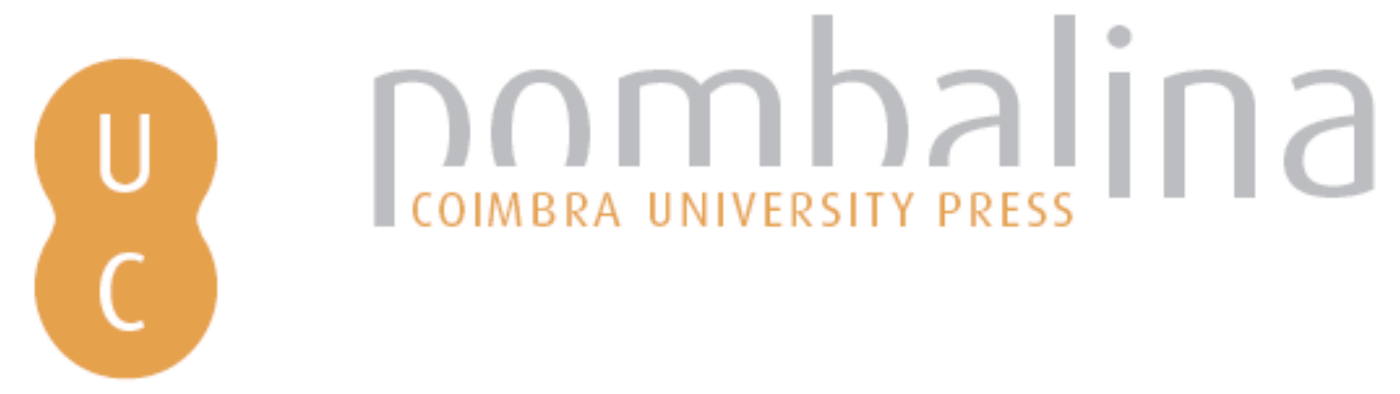

\title{
Exploring the condition-based maintenance opportunities for production-critical assets
}

\author{
Autor(es): $\quad$ Lokko, Nii Nortey Basil; Raza, Jawad; Panesar, Sukhvir Singh \\ Publicado por: Tecnologia da Universidade de Coimbra, Departamento de Engenharia \\ Mecânica \\ URL
persistente: $\quad$ URI:http://hdl.handle.net/10316.2/33314 \\ DOI: DOl:http://dx.doi.org/10.14195/978-972-8954-42-0_5 \\ Accessed : $\quad$ 26-Apr-2023 15:16:53
}

A navegação consulta e descarregamento dos títulos inseridos nas Bibliotecas Digitais UC Digitalis, UC Pombalina e UC Impactum, pressupõem a aceitação plena e sem reservas dos Termos e Condições de Uso destas Bibliotecas Digitais, disponíveis em https://digitalis.uc.pt/pt-pt/termos.

Conforme exposto nos referidos Termos e Condições de Uso, o descarregamento de títulos de acesso restrito requer uma licença válida de autorização devendo o utilizador aceder ao(s) documento(s) a partir de um endereço de IP da instituição detentora da supramencionada licença.

Ao utilizador é apenas permitido o descarregamento para uso pessoal, pelo que o emprego do(s) título(s) descarregado(s) para outro fim, designadamente comercial, carece de autorização do respetivo autor ou editor da obra.

Na medida em que todas as obras da UC Digitalis se encontram protegidas pelo Código do Direito de Autor e Direitos Conexos e demais legislação aplicável, toda a cópia, parcial ou total, deste documento, nos casos em que é legalmente admitida, deverá conter ou fazer-se acompanhar por este aviso.

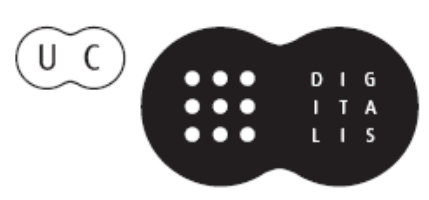




\title{
Exploring the condition-based maintenance opportunities for production-critical assets
}

\author{
Nii Nortey Basil Lokko'; Jawad Raza ${ }^{2}$; Tore Markeset ${ }^{1}$; Sukhvir Singh Panesar ${ }^{1}$

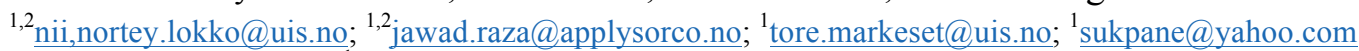 \\ ${ }^{1}$ University of Stavanger, N4012 Stavanger, Norway \\ ${ }^{2}$ Apply Sørco AS, N4012 Stavanger, Norway
}

\begin{abstract}
The optimum maintenance strategies for an installation on the Norwegian Continental Shelf (NCS) are seen as a combination of Condition-Based Maintenance (CBM), predetermined periodic Preventive Maintenance (PM) and runto-failure. CBM strategies are traditionally reserved for high safety-critical and high production-critical equipment. In recent years, however, there has been an increasing demand to maximize the use of CBM strategies on offshore installations.
\end{abstract}

Arguments are presented in this paper to explore the opportunities where CBM strategies can be justifiable for other production-critical equipment. The justification presented is thus related to the cost-effectiveness of establishing a Condition Monitoring (CM) system, which would primarily be based on the use of process and equipment performance measures.

The paper presents an intuitive explanation for the costeffective justification of CBM and also summarizes some general issues that influence the decision process for the different equipment criticality classes. A graphical representation is then presented. On the basis of analysis, a scenario is presented where CBM strategies and activities are justifiable for other production-critical equipment.

Keywords-Condition monitoring, maintenance, maintenance cost-effectiveness

condition-based

\section{INTRODUCTION}

The initial method that formed the basis for which the concept of Condition-Based Maintenance (CBM) was first introduced in the late 1940s was the trending of process parameters in the Rio Grande Railway Company [1]. The company attained some level of success in detecting leaks within its engines by trending pressure and temperature readings. This provided early evidence that trending of process parameters has the potential to yield positive results. It is such early works that inform our current definition of CBM as a maintenance program where interventions are based on information obtained by monitoring the condition of equipment [2].

Research and developments in technology since then have shown that other methods can also result in the reduction of unexpected system failures. Subsequently, the use of vibration measurements, oil particle analysis, process parameters, acoustic emission, etc., has become relatively common within mission-critical and capital-intensive industries such as process, manufacturing, railway and aviation. CBM is essential within such industries because of the high consequences of failure with respect to safety and cost. The Oil and Gas (O\&G) industry is also a mission-critical and capital-intensive industry where there are severe consequences of failure and high downtime costs. CBM is therefore considered essential to O\&G operations.

The optimum maintenance strategy for an installation on the Norwegian continental shelf (NCS) is a combination of $\mathrm{CBM}$, predetermined periodic maintenance and run-to-failure, with $\mathrm{CBM}$ as the preferred strategy wherever cost-effective. However, due to limited capital and human resources with the right competence, CBM is often reserved for some of the most critical (safety and production) systems. Medium or low critical equipment may sometimes either have predetermined periodic maintenance programs or simply be run-to-failure [3]. Veldman et al. [4] support the assertion that CBM is not yet a dominant maintenance concept. However, their matrix of CBM types (typology) suggests that a Type 1 analysis (i.e. statistical models applied to analyze pressure and temperature data) was used by the Rio Grande Railway Company when the concept of CBM was first introduced. Such analysis, supported with recent advancements in technology and analysis techniques, can be replicated for equipment that has existing predetermined periodic maintenance programs.

Increasing maintenance costs and decreasing production profile drive companies to find more efficient maintenance strategies. CBM is an example of an efficient maintenance strategy, if practical and cost-effective to implement. To minimize the effect of increasing maintenance costs and decreasing production profile, the current scope of CBM needs to be extended. The purpose of the paper is to investigate and establish the feasibility of employing condition monitoring techniques based on process parameters and performance degradation measures to implement CBM. Some principles of CBM, existing CM techniques and data-processing methods are presented in this paper. A summary of issues relating to the cost-effectiveness of CM systems on the NCS is also presented, which is followed by a discussion on opportunities to widen the scope for CBM implementation on production-critical equipment.

\section{DIAGNOSTICS VERSUS PROGNOSTICS}

Tsang [5] suggests that no matter what the CBM method, two conditions must be satisfied. Firstly, there must be a strong correlation between the data collected and the onset of failure. 
Secondly, a clear threshold value must be identified that suggests an intervention is necessary. Thus Jardine et al.'s [2] suggestion that diagnosis and prognosis are the main tasks within CBM is in support of Tsang's suggestions. The objective of diagnosis is the detection of component failure or abnormal conditions [6]. Prognosis, on the other hand, entails the prediction of remaining useful life and/or component reliability (i.e. time to failure) [2].

Some research indicates that both diagnosis and prognosis may be industrially applied [2] [3] [7] [8]. However, Garg and Deshmukh [9] suggest that most real industrial applications are more diagnostic than prognostic. Veldman et al. [4] tested this postulate and concluded from case studies that there is some evidence in support of this assertion. Though the evidence was limited, there was enough to suggest that the industrial application of CBM is for decision support and often viewed by engineers in three stages: early warning/detection of incidents, failure definition and decision-making.

\section{SOME CONDITION MONITORING (CM) TECHNIQUES}

Only after accurate and reliable data has been collected can the data then be processed for decision-making. The following are some of the most common CM techniques employed as the source for collecting equipment condition data for analysis and decision-making:

TABLE I. COMMON CM TECHNIQUES

\begin{tabular}{|l|l|}
\hline Technique & Comments and references \\
\hline $\begin{array}{l}\text { Vibration Analysis } \\
\text { VA) }\end{array}$ & $\begin{array}{l}\text { The most common CM technique [10], but it is also } \\
\text { accompanied by considerable cost implications. } \\
\text { Most commonly used in detecting defects in roll } \\
\text { element bearing [11] and wind turbines [12]. }\end{array}$ \\
\hline Oil Analysis (OA) & $\begin{array}{l}\text { OA is another common CM technique. Some defects } \\
\text { are detectible in oil samples much earlier than they } \\
\text { manifest in vibration readings [13] [14]. Despite the } \\
\text { availability of the technology of online [15], offline } \\
\text { oil sample taking is a preferred method [14]. }\end{array}$ \\
\hline $\begin{array}{l}\text { Process Parameter \& } \\
\text { Performance } \\
\text { Monitoring }\end{array}$ & $\begin{array}{l}\text { García Márquez et al. [12]suggest that maintenance } \\
\text { based on process parameters is still common } \\
\text { practice (at least in the case of wind turbines). Some } \\
\text { to as thermodynamic } \\
\text { parameter } \\
\text { monitoring) }\end{array}$ \\
$\begin{array}{l}\text { relationship between measured performance } \\
\text { parameters such as speed, power, efficiency, etc., } \\
\text { can be used for failure diagnosis. Complex } \\
\text { techniques are not employed in the analysis [14]. }\end{array}$ \\
\hline
\end{tabular}

Other techniques such as acoustic emission, thermography, strain measurement, shock pulse method, stator current harmonic measurements, etc., have been known to deliver some level of success in failure diagnosis and (to some extent) the prognosis of dynamic systems. A CM method selection chart showing a list of 18 equipment groups and $28 \mathrm{CM}$ techniques has been compiled by the British Institute of NonDestructive Testing (NDT) as a guide for selective application [18].

\section{CM DATA/SIGNAL PROCESSING METHODS}

Condition monitoring does not end at simply collecting the data obtained. A diagnosis and/or prognosis in support of decision-making must be the ultimate purpose of any $\mathrm{CM}$ activity. Two main basic elements within any CM system are: the number and type of sensors, and the corresponding signal processing and simplification methods used to convert the signals into information that can then be employed for decision-making [12].

Some of the data (signal) processing methods currently being employed include statistical methods, time-domain analysis, trend analysis (TA), filtering methods, hidden Markov models (HMM), cepstrum analysis, artificial neural networks, fuzzy logic, expert systems, time-synchronous averaging (TSA), fast Fourier transform (FFT), amplitude demodulation, order analysis and wavelet transforms.

\section{COST-EFFECTIVENESS OF CONDITION MONITORING ON THE NCS}

The unexpected failures of safety- and production-critical equipment on the NCS can be safety- and environment-critical and capital-intensive, which therefore makes them candidates for $\mathrm{CM}$ and eventually for the implementation of CBM. Increased demand for unmanned production facilities and/or personnel reduction of manned offshore installations increases the requirement for real-time, online condition assessment of equipment. Despite the increased requirement for CM, there are many challenges in implementing CBM. Some of the challenges that affect the cost-effectiveness of CBM include:

- Integrating multiple CM techniques

- High volume of sensors and related challenges

- Availability of technical CM expertise and interdisciplinary know-how

\section{A. Integrating multiple CM techniques}

Some maintenance experts on the NCS are of the opinion that a single $\mathrm{CM}$ technique is most often insufficient for equipment diagnostic and prognostic purposes. Hence, it is often quite common to have combinations of different techniques applied on one equipment unit [19]. The main conclusion is that only an integrated approach could provide the comprehensive and reliable solutions needed (see [20]).

This need for integrating multiple techniques for proper failure diagnosis and/or operational prognosis is one of the major reasons why $\mathrm{CBM}$ is not the dominant maintenance strategy on the NCS. To procure, install, operate and maintain a complete $\mathrm{CM}$ system would often require a cost build-up which is a function of the number of techniques to be integrated. After the initial capital expenditures (CAPEX) (procurement, installation, etc.), the cost of the CM system operation and maintenance expenditures (OPEX) accumulate over time. The accrued benefits of using such an integrated system of techniques must outweigh the combined CAPEX and OPEX. This life cycle cost-benefit evaluation must also include the resulting maintenance cost (increase/decrease) of the production equipment itself in the analysis. 


\section{B. High volume of sensors and related challenges}

Accurate and reliable data is necessary for effective condition monitoring and its related activities. García Márquez et al. [12] suggest that the number and type of sensors is fundamental to the accuracy and reliability of the data collected. The more quality sensors are installed, the more accurate and reliable data is collected. The numbers of reliable sensors that are needed for a single technique can become costly to install (procurement, installation and systems integration costs), operate (data collection, storage and analysis costs) and maintain (repair and replacement costs).

An example is provided by a maintenance engineer on the NCS, who stated that they have expensive vibration sensors installed on some of their equipment. However, the vibration sensors are installed in such a way that they cannot be removed without compromising their accuracy and effectiveness. Therefore, after every major maintenance activity, new vibration sensors need to be obtained and installed.

In addition, the costs related to sensor failures and unwanted stoppages with high downtime cost may increase with more sensors.

Hence, the cost of integration of CM techniques is likely to increase with respect to the number of techniques being integrated. Subsequently, justifying the expenses required for an integrated condition monitoring solution is more practicable on equipment that is highly production-critical. It may not be cost-efficient to run CBM on less critical offshore production assets. Experienced-based periodic maintenance strategies may be more cost-effective and hence a preferred maintenance strategy.

\section{Availability of technical CM expertise and interdisciplinary know-how}

Processing and analyzing data seems to be another major practical application challenge that needs to be overcome. Some maintenance engineers on the NCS are also of the opinion that several of the CM techniques are quite specialized fields of study and may be monitoring one of the many failure modes of critical equipment. Consequently, the competences required to effectively operate and manage $\mathrm{CM}$ are not readily available internally within the maintenance departments. They suggest that this is the reason why the monitoring of equipment is often wholly/partly subcontracted to specialized service providers with the required expertise.

Schlechtingen et al. [21]support the notion that the application of the $\mathrm{CM}$ techniques often requires extensive knowledge about the system to be monitored. In the absence of such knowledge, building physical models that have the desired level of accuracy becomes an even more daunting task (especially of dynamic systems with high system complexities). The absence of such know-how, compounded by a seeming lack of an interdisciplinary team approach, often manifests in the establishment of CM systems without a clearly defined framework/process to move from data/information to decision-making/intervention (CBM). Furthermore, the companies need to have organization in place that integrates the information available from CM techniques into decisionmaking processes to hinder the performance/condition degradation of monitored equipment.

Thus, if the necessary expertise is not already available within the O\&G operating company, and the cost of obtaining such expert analysis is unjustifiably high, CBM will likely be unavailable for the less production-critical equipment (and even for some highly production-critical equipment).

\section{UNDERSTANDING THE COST-EFFECTIVENESS BASELINE AND CURVE}

These issues, which have been shown to influence the costeffectiveness (and efficiency) of CBM, have become defining factors for the successful implementation of CM systems.

A CM system generally comprises: 1) the sensors and probes, 2) the local system control unit, 3) a data storage unit, and 4) a monitoring unit (which often comprises computers, screens and analysis software and applications). Each unit is often connected to the other via wireless or cable/wire connections. Figure 1 shows an overview of the lifecycle cost build-up for CM systems.

\section{Condition monitoring system cost build-up}

(A general overview)

\begin{tabular}{|c|c|c|}
\hline $\begin{array}{l}\text { CM system acquistion } \\
\& \text { installation expenses }\end{array}$ & $\begin{array}{c}\text { CM system } \\
\text { operation expenses }\end{array}$ & $\begin{array}{c}\mathrm{CM} \text { system } \\
\text { maintenance expenses }\end{array}$ \\
\hline & $7 \Gamma$ & 1 \\
\hline $\begin{array}{l}\text { - Sensors } \\
\text { - System control unit } \\
\text { - Cables \& wires (wireless routers) } \\
\text { - Installation \& systems integration } \\
\text { - Personnel training }\end{array}$ & $\begin{array}{l}\text { - Software/package licenses } \\
\text { - Data transfer \& storage } \\
\text { - Equipment monitoring \& } \\
\text { health assessment } \\
\text { - Reporting services }\end{array}$ & $\begin{array}{l}\text { - Routine CM system } \\
\text { maintenance checks } \\
\text { - Component repair/replacement } \\
\text { - CM system overhaul }\end{array}$ \\
\hline
\end{tabular}

Fig. 1. An overview of CM system cost build-up 
This life cycle cost build-up is a major factor in deciding the cost-effectiveness of the CM systems under evaluation. Any justifications for CBM implementation need to be costeffective. The cost-benefit analysis includes the added cost or cost savings that are a direct result of the condition-based activities and interventions performed on the equipment being monitored (over time). Moreover, the integration costs to integrate $\mathrm{CM}$ techniques on existing installations can further increase CAPEX.

It makes economic sense to spend more resources on safeguarding higher valued equipment than on lower valued equipment (where the resources themselves are limited). Subsequently, the limit to the amount of resources dedicated to failure prevention and/or prediction should be proportional to the equipment criticality (consequence) classification. It therefore follows that the economic threshold for CBM on high critical equipment will be greater than medium critical equipment and low critical equipment (respectively and in that order of ranking). Figure 2a, therefore, provides an intuitive reasoning for why less production-critical equipment often falls outside the cost-effective scope for CBM strategies.

Figure $2 \mathrm{a}$ shows that at a certain cost level of CBM, the level of justification required to establish the cost-effectiveness of implementing CBM is lowest for high critical equipment, and highest for low critical equipment. In other words, establishing the economic benefits of CBM is comparatively simpler for high critical equipment than for less critical equipment at the same CBM cost level. This is depicted in the slopes for each (high critical, medium critical and low critical) line. There is a minimum cost-effectiveness level (baseline) that any CM system must meet, irrespective of the equipment criticality class. This cost-effectiveness baseline will be dependent on available resources (human and capital), operational philosophy and statutory regulations. The age of the installations, business goals, organization, etc., are additional factors, which may influence the baseline and affect the implementation of CBM. The economic threshold for lower critical production equipment often falls below this minimum level. Hence CBM strategies are usually not an option for such equipment. As the CBM cost increases, the level of justification required to establish the cost-effectiveness increases accordingly. Most often, however, slight increases in $\mathrm{CBM}$ costs may push the cost-effectiveness level beyond the economic threshold for even medium critical equipment. Consequently, several of these items of critical production equipment are also not selected for CBM strategies. Hence, within the bounds of limited available resources, some items of critical equipment are the prime candidates for CM and CBM.

A curve drawn from the baseline through the points of the respective line intersections produces a CBM costeffectiveness curve, as depicted in Figure 2a.
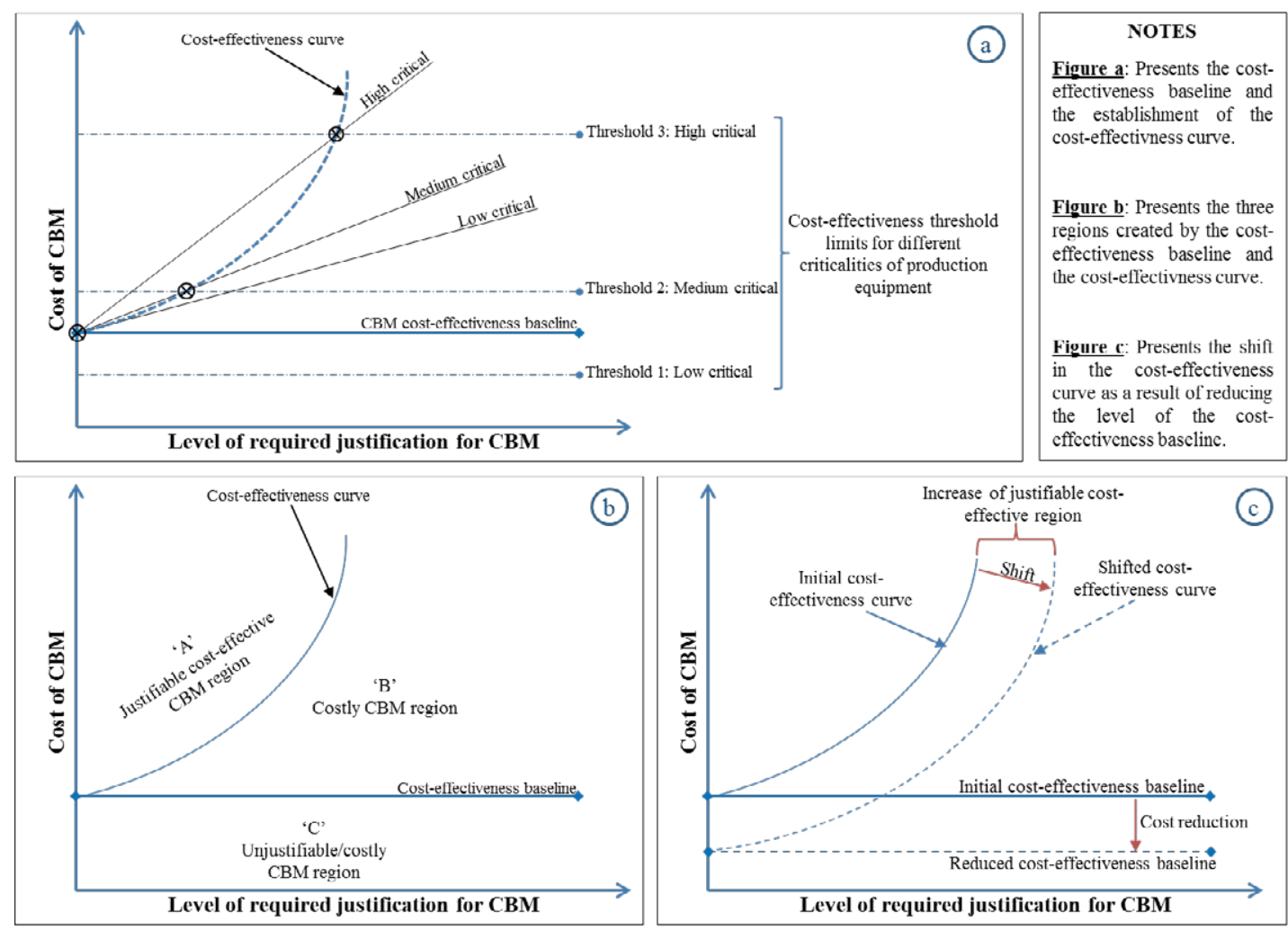

Fig. 2. The cost-effectiveness baseline \& curve, and the CBM justifiable regions 
The cost-effectiveness curve provides the boundary beyond which CBM is no longer cost-effective. Three distinct regions are created as a result of the cost-effectiveness baseline and curve. This is shown in Figure 2b. Region " $A$ " represents a zone where CBM cost-effectiveness is justifiable. In region "B", cost-effectiveness may be economically unjustifiable, but CBM strategies may still be employed for other overriding reasons (such as regulations or company policies). For region "C", CBM is not cost-effective, and no other factor can be used to justify its implementation. Thus with limited resources, only equipment that falls into region " $\mathrm{A}$ " and a selected few that fall into region " $\mathrm{B}$ " will be eligible for CBM.

If the level of CBM is to increase on the NCS, the size of region "A" will have to be increased. One way this can be achieved is by lowering the CBM cost-effectiveness baseline.

\section{INCREASING THE CBM COST-EFFECTIVENESS}

A possible remedy to the cost and expertise-related challenges is to use data that is already available. Process and/or performance data are constantly being collected and stored for operation/production purposes. Subsequently, there may be no need for the additional cost of installing, operating and maintaining specialized sensors for an integrated multitechnique CM system.

A list of $18 \mathrm{CM}$ techniques was used to compile the $\mathrm{CM}$ selection chart by the British Institute of NDT [18]. This list can be further grouped into broad categories as follows: process parameters \& performance monitoring, thermography \& thermal imaging, vibration \& noise analysis, oil \& wear analysis (tribology), and other CM techniques. An analysis of this CM selection chart suggests that performance monitoring is an appropriate $\mathrm{CM}$ technique for a majority (25 out of the 28) of the identified equipment groups. The monitoring of process parameters such as temperature and pressure (and flow) is also appropriate for a significant proportion of equipment groups (17 out of 28). A CBM strategy may, therefore, be feasible on the basis of a comparative assessment of measured performance indicators and process parameters, provided a strong and clear relationship between the parameters and possible failures is observable.

Process parameters \& performance monitoring, therefore, provide the highest opportunity for implementing CBM on various equipment types. Schlechtingen et al. [21], Müller et al. [16] and Sorensen et al. [17] support this assertion with their respective research works.

The above deduction is also supplemented with the following practical information:

- Supervisory control and data acquisition (SCADA) systems on offshore facilities are constantly collecting and recording process data (and to some extent performance data).

- Data historians (such as OSIsoft's PI System and Honeywell's Uniformance Process History Database (PHD)) are the systems backbone of O\&G production and platform operations and are therefore present for onshore support of offshore operations.
- New, improved, robust, accurate and precision sensor technologies are being developed and installed for all purposes (i.e. both for condition and process/performance monitoring). In certain cases, equipment is designed to have built-in sensors that effectively eliminate the additional sensor acquisition and related installation expenses.

- Advancements in computing and information technology (IT) provide the platform for cheaper, robust and more powerful IT infrastructure and computer hardware. Larger volumes of data can now be collected, processed and stored faster and more cheaply than previously [22]

- Wireless sensor technology is becoming more available for use.

- Improvements in advanced analysis technology such as neural networks, genetic algorithms, etc., are being used [23].

Consequently, the cost-effectiveness justification for CBM based on process and performance monitoring seems less daunting as compared to other $\mathrm{CM}$ techniques. The same process and/or performance data will be employed by maintenance personnel and process/operations personnel for analysis. Hence, the issue of a lack of collaborative, interdisciplinary approach to CBM is also tacitly addressed.

In relation to the cost-effectiveness baseline, cost reduction (across the board) is attainable if the CBM strategy is based on process and performance parameter monitoring (as shown in Figure 3). The cost-effectiveness baseline is subsequently lowered, and the cost-effectiveness curve is consequently shifted to the right (as shown in Figure 2c). Thus, this creates the opportunity for more justifiable cost-effective CBM strategies on all production equipment (irrespective of criticality classification). What remains challenging and the driving factor to this approach is obtaining the appropriate process/methodology for transforming data into diagnostic and prognostic information for decision-making.

According to Schlechtingen et al. [21], equipment behavior models can be made available to the maintenance engineer, provided that advanced analysis techniques such as neural networks and fuzzy logic can be utilized. They suggest that the use of signal (process and performance) behavior models is advantageous in the sense that prior knowledge of signal behavior is not a requirement. However, there is an intrinsic property of normal behavior models that suggests the possibility of monitoring a signal can be independent of the operational mode. Zaher et al. [24] and Sanz-Bobi et al. [25] also suggest that changes in signal behavior can be observed as early as days, weeks, and even months before failure occurs. These arguments advocate the dynamic CM capability of behavior models that are based on performance and process data. Adaptive neuro-fuzzy interference systems utilized on wind turbines is a demonstration of the potential behavioral models for CM [21]. Hence it can be concluded that there is a high possibility for utilizing cost-effective CBM strategies, even on lesser production-critical equipment on the NCS. 
CBM based on process and performance monitoring alone may not provide the complete diagnostic and/or prognostic capabilities for all equipment failure modes, but some level of $\mathrm{CM}$ on production-critical equipment is better than none at all.

\section{CONCLUDING REMARKS}

Despite the current scenario, where CBM is often justifiable on a few items of production-critical equipment on the NCS, the analysis presented in this paper suggests that CBM strategies may also be feasibly extended to other production-critical offshore assets. A limiting factor to justifying the cost-effectiveness of condition monitoring systems, on this production equipment, is identified as the lowering of the cost-effectiveness baseline. The issues identified as factors influencing the cost-effectiveness of CM systems can be successfully circumvented if the appropriate process/methodology is developed to effectively use the already available process and performance data. It is, therefore, necessary to focus on extending theoretical research works in the area of utilizing process and performance parameters for more equipment diagnostics and prognosis.

On the whole, even if technology provides the possibilities of CM, companies need to strategically evaluate and decide on the opportunities that need to be realized for complete or partial implementation of condition based maintenance. The age of the installation, business goals, operational philosophy, organization, human resources and competence, etc., are some of the additional factors that influence CBM implementation.

Condition monitoring system cost build-up

(Primarily based on process \& performance parameter monitoring)

\begin{tabular}{|c|c|c|}
\hline $\begin{array}{l}\text { CM system acquistion } \\
\& \text { installation expenses }\end{array}$ & $\begin{array}{l}\text { CM system } \\
\text { operation expenses }\end{array}$ & $\begin{array}{c}\text { CM system } \\
\text { maintenance expenses }\end{array}$ \\
\hline $\begin{array}{l}\text { - Sensors } \\
\text { - System control unit } \\
\text { - Cables \& wires (wireless routers) } \\
\text { - Installation \& systems integration } \\
\text { - Personnel training }\end{array}$ & $\begin{array}{l}\text { - Software/package licenses } \\
\text { - Data transfer \& storage } \\
\text { - Equipment monitoring \& } \\
\text { health assessment } \\
\text { - Reporting services }\end{array}$ & \multirow[t]{2}{*}{$\begin{array}{l}\text { - Routine CM system } \\
\text { maintenance checks } \\
\text { - Component repair/replacement } \\
\text { - CM system overhaul }\end{array}$} \\
\hline $\begin{array}{l}\text { Reduced CM system } \\
\text { acquisiton \& } \\
\text { installation costs }\end{array}$ & $\begin{array}{l}\text { Reduced CM system } \\
\text { operating expenses }\end{array}$ & \\
\hline $\begin{array}{l}\text { Almost no extra sensor } \\
\text { acquisition costs } \\
\text { - No additional system control unit } \\
\text { expenses } \\
\text { - No extra cables \& wires (wireless } \\
\text { routers) cxpenses } \\
\text { - Some installation \& systems } \\
\text { integration expenses } \\
\text { - Some personnel training costs }\end{array}$ & $\begin{array}{l}\text { Marginal-to-no extra charges } \\
\text { for data transfer \& storagc } \\
\text { - Little/no reporting service } \\
\text { charges }\end{array}$ & $\begin{array}{l}\text { Marginal-to-no additional cost } \\
\text { of routine CM system checks } \\
\text { - Marginal-to-no additional } \\
\text { component repair/replacement } \\
\text { costs } \\
\text { - Marginal-to-no additional } \\
\text { system overhaul costs }\end{array}$ \\
\hline
\end{tabular}

Fig. 3. Influences of the use of process and performance parameters on CM system cost build-up

\section{ACKNOWLEDGMENT}

We would like to acknowledge all asset managers and maintenance engineers from the NCS who contributed to this study.

\section{REFERENCES}

[1] Prajapati, A., Bechtel, J. and Ganesan, S., (2012), Condition-based maintenance: a survey, Journal of Quality Maintenance Engineering: 18 , pp. 384-400

[2] Jardine, A., Lin, D. and Banjevic, D., (2006), A review on machinery diagnostics and prognostics implementing condition-based maintenance, Mechanical Systems and Signal Processing: 20 (7), pp. 1483-510

[3] NORSOK Z-008, (2011), Risk based maintenance and consequence classification

[4] Veldman, J., Klingenberg, W. and Wortmann, H., (2011), Managing condition-based maintenance technology: A multiple case study in the process industry, Journal of Quality Maintenance Engineering: 17, pp. $40-62$
[5] Tsang, A., (1995), Condition-based maintenance: tools and decisionmaking, Journal of Quality in Maintenance Engineering: 1 (3), pp. 3-17

[6] Venkatasubramanian, V., Rengaswamy, R. and Kavuri, S.N., (2003), A review of process fault detection and diagnosis part II: qualitative models and search strategies, Computers and Chemical Engineering: 27 (3), pp. 313-26

[7] Heng, A., Zhang, S., Tan, A. and Mathew, J., (2009), Rotating machinery prognostics: state of the art, challenges and opportunities, Mechanical Systems and Signal Processing: 23 (3), pp. 724-39

[8] Venkatasubramanian, V. (2005), Prognostic and diagnostic monitoring of complex systems for product lifecycle management: challenges and opportunities, Computers and Chemical Engineering: 29 (6), pp. $1253-$ 63

[9] Garg, A. and Deshmukh, S.G., (2006), Maintenance management: literature review and directions, Journal of Quality in Maintenance Engineering: 12 (3), pp. 205-238

[10] Randall, R.B., (2011), Vibration-based Condition Monitoring, Wiley, Chichester, West Sussex, UK, ISBN 9780470747858

[11] Tandon, N., Yadava, G.S. and Ramakrishna, K.M., (2007), A comparison of some condition monitoring techniques for the detection of 
defect in induction motor ball bearings, Mechanical Systems and Signal Processing: 21(1), pp. 244-256.

[12] García Márquez, F.P., Tobias, A.M., Perez, J.M.P. and Papaelias, M., (2012), Condition monitoring of wind turbines: techniques and methods, Renewable Energy: 42, pp. 169-178

[13] Leske, S. and Kitaljevich, D., (2006), Managing gearbox failure, Dewek, Dewi Magazine: N. 29

[14] Verbruggen, T.W., (2003), Wind turbine operation \& maintenance based on condition monitoring, WT-O. Final report, ECN-C-03-047; April

[15] Hameed, Z., Hong, Y.S., Choa, Y.M., Ahn, S.H. and Song C.K., (2009), Condition monitoring and fault detection of wind turbines and related algorithms: a review, Renewable and Sustainable Energy Reviews: 13, pp. 1-39

[16] Müller, H., Pöller, M., Basteck, A., Tilscher, M. and Pfister, J., (2006), Grid compatibility of variable speed wind turbines with directly coupled synchronous generator and hydro-dynamically controlled gearbox. In: Sixth International Workshop on Large-Scale Integration of Wind Power and Transmission Networks for Offshore Wind Farms, Delft, NL; pp. 307-315.

[17] Rao, B.K.N., (1996), Handbook of Condition Monitoring, Elsevier Advanced Technology, Kidlington, Oxford, UK

[18] Sheng, S., (2011), Investigation of various condition monitoring techniques based on a damaged wind turbine gearbox, presented at, 8th International Workshop on Structural Health Monitoring: September 1315
[19] Kumar, R., Panesar, S.S. and Markeset, T. (2009), Development of technical integrity management services - A concept, Journal of Quality in Maintenance Engineering: 15 (3), pp. 271-284

[20] Schlechtingen, M., Santos, I.F. and Achiche, S., (2013), Wind turbine condition monitoring based on SCADA data using normal behavior models Part 1, System description, Applied Soft Computing: 13, pp. 259-270

[21] Sorensen, B.F., Lading, L., Sendrup, P., McGugan, M., Debel, C.P., Kristensen, O.J.D., et al., (2002), Fundamentals for remote structural health monitoring of wind turbines blades - A pre-project, Riso-R-1336 (EN)

[22] Lee, J., Ni, J., Djurdjanovic, D., Qiu, H. and Liao, H., (2006), Intelligent prognostics tools and e-maintenance, Computers in Industry: 57 (6), pp. 476-489

[23] Lee, J., Wu, F., Zhao, W., Ghaffari, M., Liao, L. and Siegel, D., (2014), Prognostics and health management design for rotary machinery systems - Reviews, methodology and applications, Mechanical Systems and Signal Processing: 42, pp. 314-334

[24] Zaher, A., McArthur, S.D.J., Infield, D.G., and Patel, Y., (2009), Online wind turbine fault detection through automated SCADA data analysis, Wind Energy: 12, pp. 574-593

[25] Sanz-Bobi, M.A., del Pico, J. and Garcia, M.C., (2006), SIMAP: Intelligent system for predictive maintenance application to the health condition monitoring of a wind turbine gearbox, Computers in Industry: 57, pp. 552-568 